International Journal of Electrical and Power Engineering 6 (1): 32-37, 2012

ISSN: 1990-7958

(C) Medwell Journals, 2012

\title{
Optimization of Proportional-Integral-Differential Controller for Wind Power Plant Using Particle Swarm Optimization Technique
}

\author{
${ }^{1}$ M.A. Ebrahim, ${ }^{2}$ K.A. El-Metwally, F.M. ${ }^{1}$ Bendary and ${ }^{1}$ W.M. Mansour \\ ${ }^{1}$ Department of Electrical Power and Machines, Faculty of Engineering at Shoubra, \\ Benha University, Cairo, Egypt \\ ${ }^{2}$ Department of Electrical Power and Machines, Faculty of Engineering at Cairo, \\ Cairo University, Cairo, Egypt
}

\begin{abstract}
This study demonstrates the use of a novel Particle Swarm Optimization (PSO) Technique for optimizing the parameters of blade pitch PID controller for wind power plant. A Proportional-Integral-Differential (PID) controller is applied to a multivariable blade pitch controller for a wind turbine generating system comprising of a wind turbine driving a 3-phase synchronous generator connected to a large power system. The optimal PID parameters search is formulated as an optimization problem with a standard eigenvalue objective function. The system's time domain simulation is then used in conjunction with the particle swarm optimizer to determine the controller gains taking into consideration the eigenvalue-based performance index. Simulation results significantly clarify the effectiveness of the proposed PSO based blade pitch controller and its flexibility towards improving the system's dynamic behavior and enhancing the system's stability under parameter uncertainties. The superiority of the proposed control technique over conventional PID controller is justified in presence of parameter uncertainties.
\end{abstract}

Key words: Particle Swarm Optimization Technique, wind energy conversion, wind turbine control, synchronous generator, effectiveness, Egypt

\section{INTRODUCTION}

Wind Energy (WE) is one of the most prominent sources of electrical energy in years to come. WE, as a Renewable Energy (RE) can produce energy with neither catastrophic climate issues nor Green House Gases (GHG) emissions in addition to its sustainable manner for energy production. The increasing concerns to environmental issues demand the search for more sustainable electrical sources. Wind turbines along with solar energy and fuel cells are possible solutions for the environmental-friendly energy production. WE is a non-depleting, site-dependant, non-polluting and a potential source of the alternative energy option. Researchers could supply $12 \%$ of global electricity demand by 2020 , according to a report by International Renewable Energy Agency (IRENA). The installed capacity of WE in Egypt was about 3\% of the total electricity production from RE sources in October, 2010. Egypt has committed to generate $20 \%$ of its total electricity production from RE sources by 2020 . On the other hand, France has the third largest wind resource in Europe after Germany and UK. In 2010, 21\% of the French electricity consumption was supplied by RE sources. Wind power presented $75 \%$ of the additional production in 2010 .

WE has already reached a penetration level in some areas world wide which raises some technical problems concerning grid integration. Wind power has to overcome some technical as well as economical barriers if it should produce a substantial part of electricity (Rosas, 2003). In power systems, the objective of the control strategy is to generate and deliver power as economical and reliable as possible while maintaining the voltage and frequency within permissible limits (Saadat, 2002; Kundur, 1994). In order to improve the performance of the blade pitch control system, the PID controller is normally used, since it has simpler structure. Linear control theory is usually employed to the blade pitch controller design. Therefore control laws on the basis of the linearised model with fixed system parameters are developed. Blade pitch control system of the wind turbine plant is of high order and non-linear. The controller design based on a fixed parameter model may not work properly for the actual plants. The control of such systems which have the characteristics of parameter inaccuracy, structured and

Corresponding Author: M.A. Ebrahim, Department of Electrical Power and Machines, Faculty of Engineering at Shoubra, Benha University, Cairo, Egypt 
unstructured uncertainty, neglected dynamics as well as time varying has been a serious challenge to the control community. To overcome these difficulties, many techniques are used recently such as Neural Network (NN), Fuzzy Logic and Genetic Algorithm (GA) (Visioli, 2001; Krohling and Rey, 2001; Mitsukura et al., 1999; Seng et al., 1999; Kawae and Tagami, 1997; Astrom et al., 1993). Artificial Intelligence (AI) techniques have also been used in PID controller parameters tuning. However, the drawbacks of these techniques are their high computation time, incapability in optimizing the objective functions and their correlated controller coefficients. Consequently, the probability of reaching to the undesired local optimal is increased. Recently, the novel PSO has been used for adjusting the PID controller parameters. It is featured by its significant capability for dealing with continuous non-linear optimization problems, shorter calculation and simulation time besides its better convergence characteristics compared to other stochastic techniques (Kennedy and Eberhart, 1995). Thus, the PSO Technique for designing the PID controller of blade pitch control system is addressed.

The rest of the study is organized as follows; the modeling of the Wind Turbine Generation (WTG) System is presented. The novel PSO based PID control design for WTG System is developed and exhibited. The optimization technique based on PSO briefly explained in simulation study that illustrates the effectiveness of the proposed PSO approach.

\section{MATERIALS AND METHODS}

Plant dynamic model: Electric power system is a complex nonlinear dynamic system. The operation objective of the wind turbine plant is to convert the kinetic energy of the wind first into mechanical energy at the turbine shaft and then into electrical energy. A simple blade pitch PID controller of a wind turbine plant block diagram is shown in Fig. 1. The system parameters and operating conditions are shown in the Table 1 and 2 (Bensenouci, 2006). The dynamic model of the system where the variables shown represent small displacements around a selected operating point can be written as; Synchronous generator:

$$
\begin{gathered}
\dot{\delta}=\omega \\
\dot{\omega}=\frac{\omega_{0}}{2 \mathrm{~h}}\left(\mathrm{~T}_{\mathrm{m}}-\mathrm{T}_{\mathrm{e}}\right) \\
\dot{\mathrm{e}}_{\mathrm{q}}=-\frac{\mathrm{K}_{4}}{\tau_{\mathrm{d} \mathrm{o}}^{\prime}} \delta-\frac{1}{\tau_{\mathrm{d} 0}^{\prime} \mathrm{K}_{3}} \mathrm{e}_{\mathrm{q}}+\frac{1}{\tau_{\mathrm{d} o}^{\prime}} \mathrm{V}_{\mathrm{f}}
\end{gathered}
$$

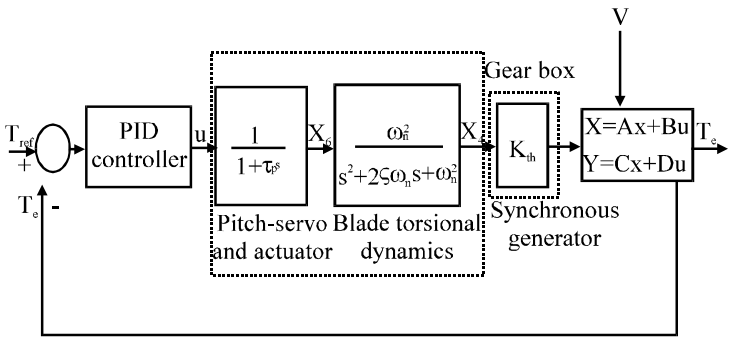

Fig. 1: Block diagram of blade pitch PID controller of a wind turbine

Table 1: Operating conditions

\begin{tabular}{ll}
\hline Parameters & Values \\
\hline Infinite bus voltage & $\mathrm{V} \infty=1$ \\
Reactive power & $\mathrm{Q}=0.6$ \\
Active power & $\mathrm{P}=0.8$ \\
Gear ratio & $\mathrm{N}=37.5$ \\
Torque factor & $\mathrm{Kth}=11.86$ \\
\hline
\end{tabular}

Table 2: System data

\begin{tabular}{ll}
\hline Parameters & Values \\
\hline Transmission line resistance & $\mathrm{R}_{\mathrm{t}}=0$ \\
Transmission line reactance & $\mathrm{X}_{\mathrm{tl}}=0.02$ \\
Turbine speed r.p.m & $\mathrm{N}_{\mathrm{r}}=40$ \\
Blade radius & $\mathrm{r}_{\mathrm{b}}=62.5$ \\
Wind speed m sec ${ }^{-1}$ & $\mathrm{~V}_{\mathrm{W}}=10$ \\
No. of poles & $\mathrm{PP}=4$ \\
Inertia constant & $\mathrm{h}=9.5$ \\
Zeta & $\zeta=0.02$ \\
Generator armature resistance & $\mathrm{R}_{\mathrm{a}}=0.018$ \\
D-axis reactance & $\mathrm{X}_{\mathrm{d}}=2.21$ \\
Q-axis reactance & $\mathrm{X}_{\mathrm{q}}=1.064$ \\
Transient d-axis reactance & $\mathrm{X}_{\mathrm{d}^{\prime}}=0.165$ \\
Subtransient d-axis reactance & $\mathrm{X}_{\mathrm{d}^{\prime \prime}}=0.128$ \\
Subtransient q-axis reactance & $\mathrm{X}_{\mathrm{q}^{\prime \prime}}=0.193$ \\
D-axis transient field time constant & $\tau_{\mathrm{do}^{\prime}}=1.94212$ \\
Q-axis subtransient field time constant & $\tau_{\mathrm{do}}=0.01096$ \\
Q-axis subtransient field time constant & $\tau_{\mathrm{qo}^{\prime \prime}}=0.0623$ \\
Angular speed of the generator [rad sec $\left.{ }^{-1}\right]$ & $\omega_{\mathrm{o}}=100 \pi$ \\
$\omega_{\mathrm{n}}$ & $\omega_{\mathrm{n}}=100$ \\
Wind turbine filter time constant & $\tau_{\mathrm{p}}=1 /\left(2^{*} 2.7^{*} \pi\right)$ \\
Exciter time constant & $\tau_{\mathrm{e}}=0.05$ \\
Exciter gain & $\mathrm{K}_{\mathrm{e}}=30$ \\
\hline &
\end{tabular}

Exciter gain

$$
\dot{\mathrm{V}}_{\mathrm{f}}=-\frac{\mathrm{K}_{\mathrm{e}} \mathrm{K}_{4}}{\tau_{\mathrm{e}}} \delta-\frac{\mathrm{K}_{\mathrm{e}} \mathrm{K}_{6}}{\tau_{\mathrm{e}}} \mathrm{e}_{\mathrm{q}}-\frac{1}{\tau_{\mathrm{e}}} \mathrm{V}_{\mathrm{f}}
$$

Blade torsional dynamics:

$$
\begin{gathered}
\dot{\mathrm{X}}_{4}=\mathrm{X}_{5} \\
\dot{\mathrm{X}}_{5}=-\omega_{\mathrm{n}}^{2} \mathrm{X}_{4}-2 \zeta \omega_{\mathrm{n}} \mathrm{X}_{5}+\omega_{\mathrm{n}}^{2} \mathrm{X}_{6}
\end{gathered}
$$

Pitch servo and actuator:

$$
\dot{\mathrm{X}}_{6}=-\frac{1}{\tau_{\mathrm{p}}} \mathrm{X}_{6}+\frac{1}{\tau_{\mathrm{p}}} \mathrm{u}
$$


PID controller:

$$
\begin{gathered}
\mathrm{u}=\mathrm{K}_{\mathrm{p}}\left(\mathrm{T}_{\text {ref }}-\mathrm{T}_{\mathrm{e}}\right)+\mathrm{X}_{7}+\mathrm{K}_{\mathrm{d}} \mathrm{s}\left(\mathrm{T}_{\text {ref }}-\mathrm{T}_{\mathrm{e}}\right) \\
\dot{\mathrm{X}}_{7}=\mathrm{K}_{\mathrm{i}}\left(\mathrm{T}_{\text {ref }}-\mathrm{T}_{\mathrm{e}}\right)
\end{gathered}
$$

With:

$$
\mathrm{T}_{\mathrm{e}}=\mathrm{K}_{1} \delta+\mathrm{K}_{2} \mathrm{e}_{\mathrm{q}}
$$

The model Eq. 1-10 can be rewritten in state space as:

Where:

$$
\dot{\mathrm{x}}(\mathrm{t})=\mathrm{Ax}(\mathrm{t})+\mathrm{Bu}(\mathrm{t})
$$

$$
\begin{aligned}
& \mathrm{x}(\mathrm{t})=\left[\begin{array}{llllllll}
\delta & \omega & \mathrm{e}_{\mathrm{q}} & \mathrm{V}_{\mathrm{f}} & \mathrm{X}_{4} & \mathrm{X}_{5} & \mathrm{X}_{6} & \mathrm{X}_{7}
\end{array}\right]^{\mathrm{t}} \\
& \mathrm{A}=\left[\begin{array}{cccccccc}
0 & 1 & 0 & 0 & 0 & 0 & 0 & 0 \\
-\frac{\omega_{0} \mathrm{~K}_{1}}{2 \mathrm{~h}} & 0 & -\frac{\omega_{0} \mathrm{~K}_{2}}{2 \mathrm{~h}} & 0 & \frac{\omega_{0} \mathrm{~K}_{\mathrm{th}}}{2 \mathrm{~h}} & 0 & 0 & 0 \\
-\frac{\mathrm{K}_{4}}{\tau_{\mathrm{d} 0}^{\prime}} & 0 & -\frac{1}{\tau_{\mathrm{d} 0}^{\prime} \mathrm{K}_{3}} & \frac{1}{\tau_{\mathrm{do}}^{\prime}} & 0 & 0 & 0 & 0 \\
-\frac{\mathrm{K}_{\mathrm{e}} \mathrm{K}_{\mathrm{s}}}{\tau_{\mathrm{e}}} & 0 & -\frac{\mathrm{K}_{\mathrm{e}} \mathrm{K}_{6}}{\tau_{\mathrm{e}}} & -\frac{1}{\tau_{\mathrm{e}}} & 0 & 0 & 0 & 0 \\
0 & 0 & 0 & 0 & 0 & 1 & 0 & 0 \\
0 & 0 & 0 & 0 & -\omega_{\mathrm{n}}^{2} & -2 \zeta \omega_{\mathrm{n}} & \omega_{\mathrm{n}}^{2} & 0 \\
\mathrm{a}_{1} & \mathrm{a}_{2} & \mathrm{a}_{3} & -\frac{\mathrm{K}_{\mathrm{d}} \mathrm{K}_{2}}{\tau_{\mathrm{d0}}} \tau_{\mathrm{p}} & 0 & 0 & \frac{1}{\tau_{\mathrm{p}}} & \frac{1}{\tau_{\mathrm{p}}} \\
-\mathrm{K}_{\mathrm{i}} \mathrm{K}_{1} & 0 & -\mathrm{K}_{\mathrm{i}} \mathrm{K}_{2} & 0 & 0 & 0 & 0 & 0
\end{array}\right]
\end{aligned}
$$

With:

$$
\begin{gathered}
\mathrm{a}_{1}=\left[\frac{\mathrm{K}_{\mathrm{d}} \mathrm{K}_{2} \mathrm{~K}_{4}}{\tau_{\mathrm{p}} \tau_{\mathrm{do}}^{\prime}}-\frac{\mathrm{K}_{\mathrm{p}} \mathrm{K}_{1}}{\tau_{\mathrm{p}}}\right], \mathrm{a}_{2}=-\frac{\mathrm{K}_{\mathrm{d}} \mathrm{K}_{1}}{\tau_{\mathrm{p}}} \\
\mathrm{a}_{3}=\left[\frac{\mathrm{K}_{\mathrm{d}} \mathrm{K}_{2}}{\tau_{\mathrm{p}} \tau_{\mathrm{do}} \mathrm{K}_{3}}-\frac{\mathrm{K}_{\mathrm{p}} \mathrm{K}_{2}}{\tau_{\mathrm{p}}}\right] \\
\mathrm{B}^{\mathrm{t}}=\left[\begin{array}{ccccccc}
0 & 0 & 0 & 0 & 0 & \frac{\mathrm{K}_{\mathrm{p}}}{\tau_{\mathrm{p}}} & \mathrm{K}_{\mathrm{i}} \\
0 & \frac{\omega_{0}}{2 \mathrm{~h}} & 0 & 0 & 0 & 0 & 0
\end{array}\right] \\
\mathrm{u}^{\mathrm{t}}=\left[\mathrm{T}_{\mathrm{ref}}, \mathrm{v}\right]
\end{gathered}
$$

PSO based PID controller design: Let the PID controller be implemented as:

$$
\frac{\mathrm{u}}{\mathrm{T}_{\text {ref }}-\mathrm{T}_{\mathrm{e}}}=\mathrm{G}_{\mathrm{c}}(\mathrm{s})=\left(\mathrm{K}_{\mathrm{p}}+\frac{\mathrm{K}_{\mathrm{i}}}{\mathrm{s}}+\mathrm{K}_{\mathrm{d}} \mathrm{s}\right)
$$

Let $\mathrm{R}_{\mathrm{i}}$ denote the real part of the poorly damped electromechanical mode eigenvalue of the system and define the eigenvalue-based objective function as:

$$
\mathrm{J}=\min \left\{\mathrm{R}_{\mathrm{i}}\right\}
$$

In this study, it is aimed to minimize the performance index $\mathrm{J}$ in order to increase the damping of the poorly damped electromechanical modes. The performance index $\mathrm{J}$ is minimized under the following constraints:

$$
\begin{aligned}
& \mathrm{K}_{\mathrm{P}_{\text {min }}} \leq \mathrm{K}_{\mathrm{P}} \leq \mathrm{K}_{\mathrm{P}_{\text {max }}} \\
& \mathrm{K}_{\mathrm{i}_{\min }} \leq \mathrm{K}_{\mathrm{i}} \leq \mathrm{K}_{\mathrm{imax}_{\text {max }}} \\
& \mathrm{K}_{\mathrm{d} \min } \leq \mathrm{K}_{\mathrm{d}} \leq \mathrm{K}_{\mathrm{d} \text { max }}
\end{aligned}
$$

Cleary, this is a nonlinear optimization problem.

PSO Technique: PSO is a population-based stochastic optimization algorithm modeled after the simulation of the social behavior of bird and fish school. This optimization technique was first introducing by Kennedy and Eberhart (1995). PSO is basically developed through simulation of bird flocking in two-dimension space. The position of each agent is represented by $\mathrm{X}-\mathrm{Y}$ axis position and also the velocity is expressed by $V_{z}$ (the velocity of $X$-axis) and $\mathrm{V}_{\mathrm{y}}$ (the velocity of Y-axis). Modification of the agent position is realized by the position and velocity information. The particles are flown through the search space by updating the position of the ith particle at time step $t$ according to Eq. 15:

$$
\mathrm{x}_{\mathrm{i}}(\mathrm{t}+1)=\mathrm{x}_{\mathrm{i}}(\mathrm{t})+\mathrm{v}_{\mathrm{i}}(\mathrm{t}+1)
$$

The velocity updates are governed by Eq. 16 :

$$
\begin{aligned}
\mathrm{v}_{\mathrm{i}}(\mathrm{t}+1)= & \sigma \mathrm{v}_{\mathrm{i}}(\mathrm{t})+\mathrm{c}_{1} \mathrm{r}_{\text {and }} \times\left(\text { pbest }_{\mathrm{i}}-\mathrm{x}_{\mathrm{i}}(\mathrm{t})\right. \\
& +\mathrm{c}_{2} \text { rand }_{2} \times\left(\text { gbest }-\mathrm{x}_{\mathrm{i}}(\mathrm{t})\right.
\end{aligned}
$$

Where:

$\mathrm{x}_{\mathrm{i}}(\mathrm{t})=$ The vector of current position

$v_{i}(t+1)=$ The vector of the current velocity

$\sigma=$ Inertia weighting function

$\mathrm{c} \quad=$ Acceleration constant

rand $=$ Random number on the interval $[0,1]$

pbest $_{\mathrm{i}}=$ Personal best of particle $\mathrm{i}$

gbest $=$ Global best (best of pbest of the group)

The inertia weighting function $\sigma$ that has been mentioned in Eq. 16 is a linearly decreasing function. The parameter selection of this function is examined by Shi and Eberhart (1998). According to their examination, 
Int. J. Elec. Power Eng., 6 (1): 32-37, 2012

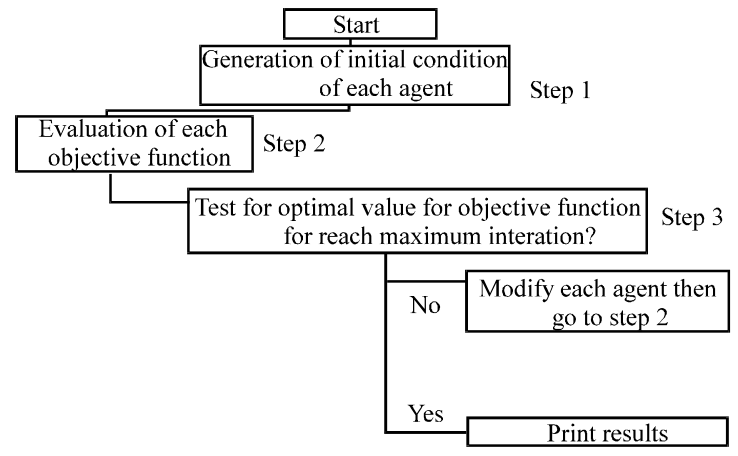

Fig. 2: A general flow chart of PSO

the parameters are ranged from about 0.9-0.4 during iterations procedure (Schi and Eberhart, 1998; Shi and Eberhart, 1998). The general flow chart of PSO can be described as:

- Step 1; generation of initial condition of each agent

- Step 2; evaluation of searching point of each agent (the objective function value is calculated for each agent)

- Step 3; checking stopping criterion

- Step 4; modification of each searching point (Fig. 2)

\section{RESULTS AND DISCUSSION}

The simulation is done using Matlab platform. For the blade pitch PID control system comprises of a wind turbine driving a 3-phase synchronous generator connected to a large power system as shown in Fig. 1. To evaluate the quality of the proposed controller design technique, it is compared with a classical tuning algorithm (General Ziegler Nichols second method of tuning) (Glover, 1986) in order to investigate the necessity of supplementary control signal attained from the PSO-PID. To demonstrate the effectiveness of the proposed controller, several tests are carried out for the wind power plant described earlier and the results are compared in case of using either GZN-PID or PSO-PID controllers. Table 3 shows the controller gains obtained. In order to inspect their robustness, the controllers are applied to the system with two different magnitudes of step load disturbances; namely, -10 and $10 \%$. Another test of robustness is performed by using the following parameters change, an increase by $25 \%$ in the field transient time constant $\tau_{\mathrm{do}}$, inertia constant $h$, developed torque gain $\mathrm{Kth}$, machine parameters $\mathrm{K}_{2}$ and $\mathrm{K}_{3}$, time constant of servo-actuator $\tau_{p}$. In the following first three tests, the wind speed is held to its nominal value.

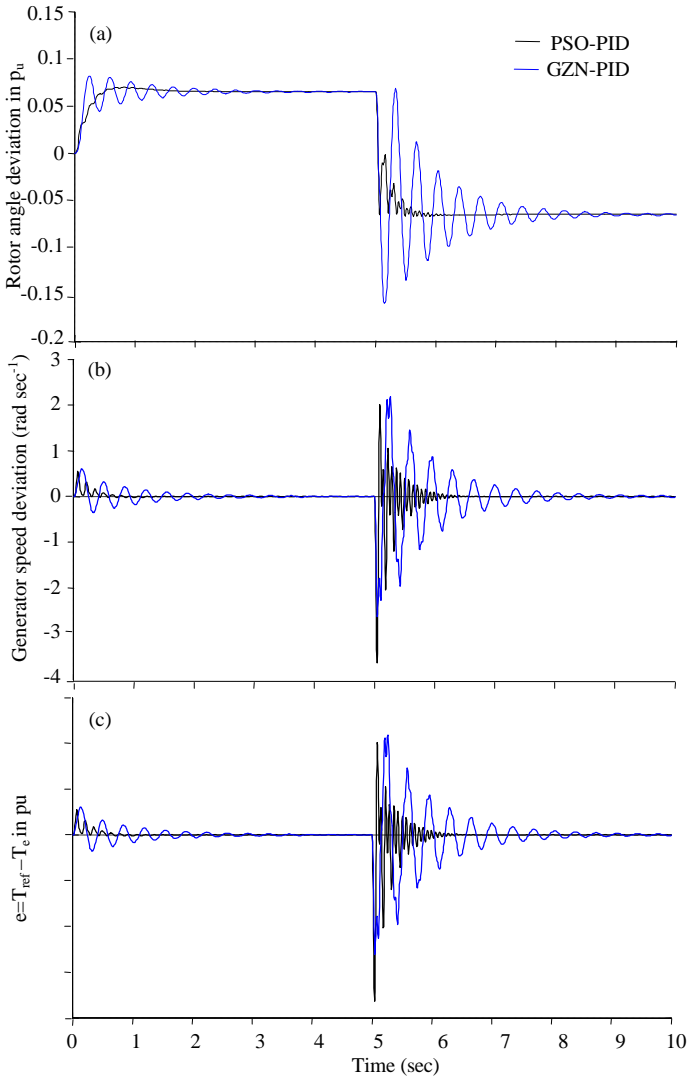

Fig. 3: Step-response following $\mathrm{T}_{\text {ref }}=+10 \%$ then $-10 \%$; a) rotor angle $\delta$ deviation; b) generator speed $\omega$ deviation; c) torque error $\mathrm{e}$

Table 3: Controllers gains

\begin{tabular}{lccc}
\hline Margin & $\mathrm{K}_{\mathrm{P}}$ & $\mathrm{K}_{\mathrm{i}}$ & $\mathrm{K}_{\mathrm{d}}$ \\
\hline GZN-PD & 0.567 & 0.039 & 2.062 \\
PSO-PID & 1.276 & 0.185 & 2.169 \\
\hline
\end{tabular}

Test 1; step response (regulation): To test the effectiveness of the system equipped with the proposed controllers, the system is subjected to a series of disturbance an increase by $10 \%$ then a decrease by $10 \%$ in $\mathrm{T}_{\text {ref }}$ (regulation) at $\mathrm{t}=5 \mathrm{sec}$. The time response of the rotor angle deviation $\delta$, generator speed deviation $\mu$ and torque error e are shown in Fig. 3. The oscillations of the transient response of the system are improved significantly compared to GZN-PID. In addition, the settling time is reduced compared to GZN-PID during the sudden change in the controlled value.

Test 2; parameters variation: To test the robustness to parameters change, an increase by $25 \%$ in the field transient time constant $\tau_{\text {do' }}$, inertia constant $h$, developed torque gain $\mathrm{Kth}$, machine parameters $\mathrm{K}_{2}$ and $\mathrm{K}_{3}$, time constant of servo-actuator $\tau_{p}$. Figure 4 shows the system 
Int. J. Elec. Power Eng., 6 (1): 32-37, 2012

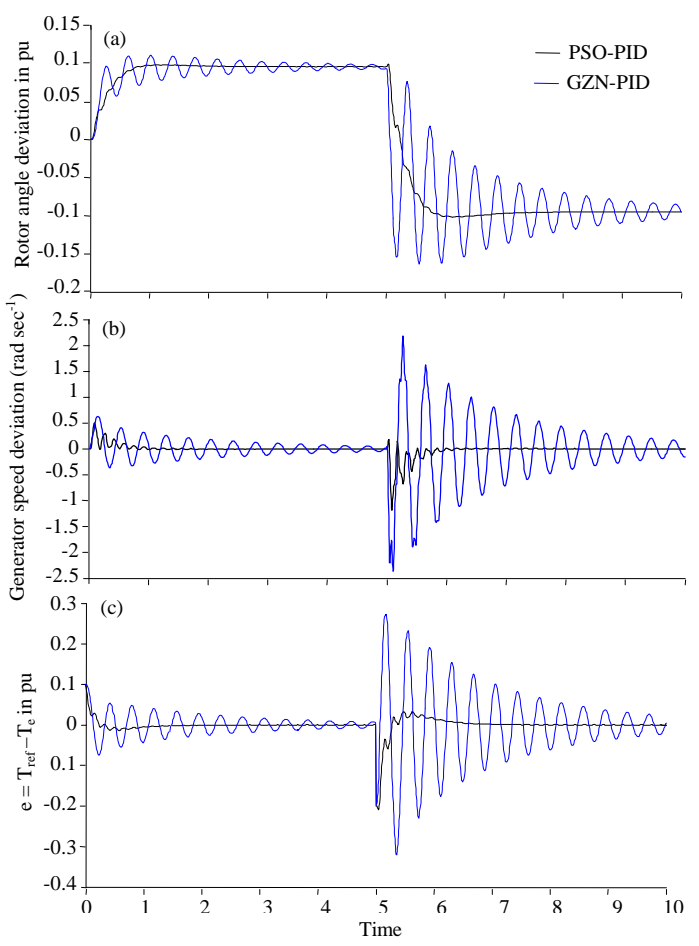

Fig. 4: Step-response following $\mathrm{T}_{\mathrm{ref}}=+10 \%$ then $-10 \%$; a) Rotor angle $\delta$ deviation; b) Generator speed $\omega$ deviation; c) Torque error $\mathrm{e}$

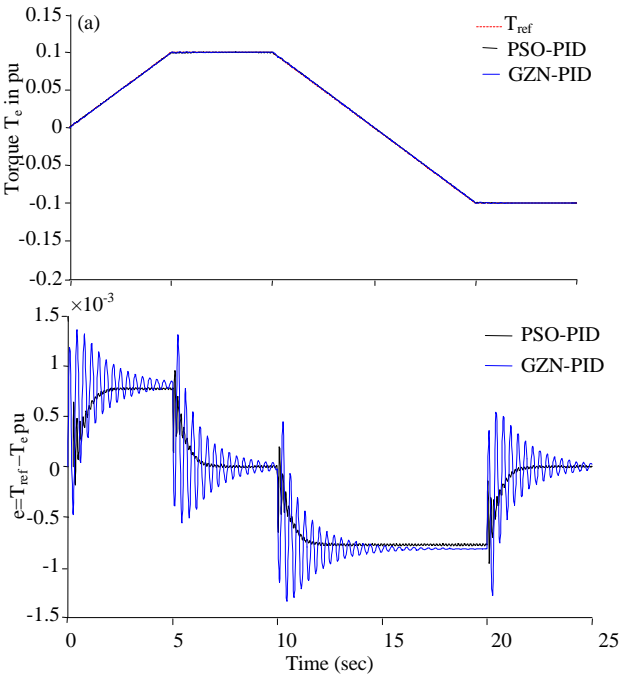

Fig. 5: Tracking the reference torque $\mathrm{T}_{\text {ref; }}$ a) Electromagnetic torque $T_{e} ; b$ ) Torque error e

response following a change in $\mathrm{T}_{\text {ref }}$ by $+10 \%$ then by $-10 \%$. Clearly, the system responds smoothly with lower settling time for PSO-PID. For GZN-PID, undesired overshoots and undershoots are displayed.

Test 3; tracking response: To test the effectiveness of the system to track the reference value of the torque $T_{\text {refo }}$
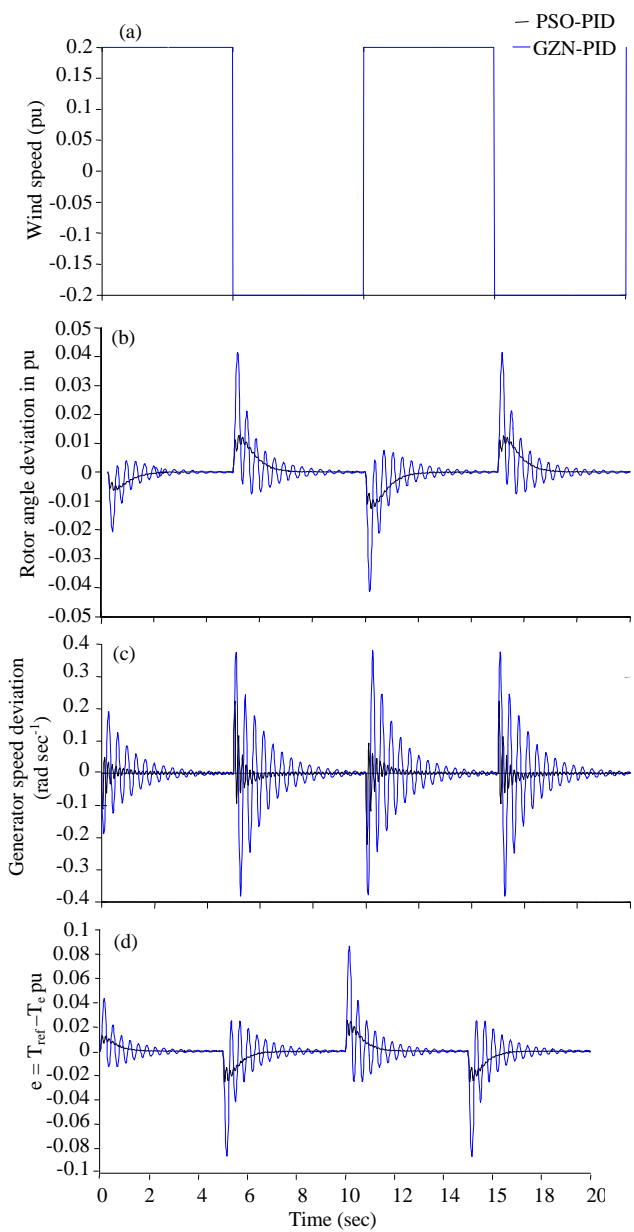

Fig. 6: Step-response following wind variation (gust); a)Wind speed variation (gust); b) Rotor angle $\delta$ deviation; c) Generator speed $\omega$ deviation; d) Torque error e

the system is subjected to a variation of $\mathrm{T}_{\text {ref }}$ as shown in Fig. 5. The system response shows excellent tracking behaviour for PSO-PID.

Test 4; wind speed variation (Gust) effect: Wind gust is a sudden, brief increase in speed of the wind. To test the robustness of the system to the wind speed variation, a gust shown in Fig. 6a is applied. Figure 6b-d shows the rotor angle deviation $\delta$ generator speed deviation $\omega$ and torque error $\mathrm{e}$ behaviour following this type of disturbance. It is clear that for this specific condition, PSO-PID shows more robustness than GZN-PID.

\section{CONCLUSION}

For a nonlinear power system comprising a wind turbine driving a synchronous generator and connected 
to an infinite bus via a step-up transformer and a transmission line where parameter uncertainties are involved in the plant operation, the design of PSO-PID controller which is robust under all possible normal and abnormal situations is thus explicitly presented in this study. After developing the system mathematical model, the novel PID controller based on PSO is developed. The PSO technique is significantly used for parameters optimal tuning of blade pitch PID controller for wind power plant. Finally, Matlab simulation results verify the outstanding performance of PSO-PID approach, its capability to stabilize the system and to improve its dynamic behaviour, its shorter simulation time, besides the controller's robustness in presence of parameters uncertainties such as the abrupt change in $T_{\text {ref }}$ disturbances, wind variation. The superiority of this controller compared to the GZN-PID one is displayed. The future research will comprise the validation of the proposed controller in the presence of system uncertainties (with more detailed model) to large and more complex power systems.

\section{ACKNOWLEDGEMENTS}

The researchers gratefully acknowledge the support of Ministry of Higher Education and Research, ASRT, Benha and Zagazig Universities from Egypt. Ministry of Foreign and European Affairs, Ministry of Higher Education and Research and Egide from France.

\section{REFERENCES}

Astrom, K.J., T. Hagglund, C.C. Hang and W.K. Ho, 1993. Automatic tuning and adaptation for PID controllersA survey. Control Eng. Practice, 1: 699-714.

Glover, F., 1986. Future paths for integer programming and links to artificial intelligence. Comput. Operat. Res., 13: $533-549$.
Kawae, T. and T. Tagami, 1997. A real-coded genetic algorithm for matrix inequality design approach of robust PID controller with two degree of freedom. Proceedings of the International Symposium on Intelligent Control, July 16-18, 1997, Istanbul, Turkey, pp: 119-124.

Kennedy, J. and R. Eberhart, 1995. Particle swarm optimization. Proc. IEEE Int. Conf. Neural Networks, 4: $1942-1948$.

Krohling, R.A. and J.P. Rey, 2001. Design of optimal disturbance rejection PID controllers using genetic algorithms. IEEE Trans. Evol. Comput., 5: 78-82.

Kundur, P., 1994. Power System Stability and Control. 1st Edn., McGraw-Hill Professional, USA., ISBN-10: $007035958 \mathrm{X}$.

Mitsukura, Y., T. Yamamoto and M. Kaneda, 1999. A design of self-tuning PID controllers using a genetic algorithm. Proceedings of the American Control Conference, January 2-4, 1999, San Diego, CA., pp: 1361-1365.

Rosas, P., 2003. Dynamic influences of wind power on the power system. Ph.D. Thesis, Technical University of Denmark.

Saadat, H., 2002. Power System Analysis. Tata McGrawHill, USA.

Seng, T.L., M.B. Khalid and R. Yusof, 1999. Tuning of a neuro-fuzzy controller by genetic algorithm. IEEE Trans. Syst. Man Cybern. Part B, 29: 226-236.

Shi, Y. and R. Eberhart, 1998. A modified particle swarm optimizer. Proceedings of the IEEE Congress on Evolutionary Computation, May 4-9, 1998, Piscataway, New Jersey, pp: 69-73.

Shi, Y. and R.C. Eberhart, 1998. Parameter selection in particle swarm optimization. Proceedings of the 7 th Internationl Conference on Evolutionary Programming, March 25-27, 1998, Springer-Verlag, London, UK., pp: 591-600.

Visioli, A., 2001. Tuning of PID controllers with fuzzy logic. IEE Proc. Control Theor. Appl., 148: 1-8. 